\title{
SUSTAINABLE CONSUMPTION AND SEGMENTATION OF POTENTIAL LOW EMISSION VEHICLE BUYERS
}

doi: $\quad 10.2478 /$ czoto-2019-0055

Date of submission of the article to the Editor: 03/11/2018

Date of acceptance of the article by the Editor: 22/12/2018

\author{
Matevž Obrecht ${ }^{1}$ - orcid id: 0000-0001-8301-7382 \\ Matjaž Knez ${ }^{1}$ - orcid id: 0000-0003-2476-2395 \\ Andrej Lisec ${ }^{1}$ - orcid id: 0000-0003-2472-8752 \\ Aleksandra Wrzalik ${ }^{2}$ - orcid id: 0000-0002-3859-4954 \\ Rebeka Kovačič Lukman ${ }^{1}$ - orcid id: 0000-0001-6733-9584 \\ 1University of Maribor, Faculty of Logistics - Slovenia, matevz.obrecht@um.si \\ ${ }^{2}$ Czestohova University of Technology - Poland
}

\begin{abstract}
In 2015 the Agenda 2030 was introduced, framed of 17 sustainable development goals (SDG) with 169 targets, which were adopted by the United Nations Member States and should bring prosperity and growth to the global society. In this paper a focus is given to the SDG 12 Sustainable consumption and production from the e-mobility perspective. SDG 12 aims to ensure sustainable consumption and production (SCP) patterns - it is about promoting resource and energy efficiency, sustainable infrastructure, and providing access to basic services, green and decent jobs, and a better quality of life for all. Many stakeholders from public and private sector are investing a lot of effort to identify consumer behaviour for future improvements in development of their green products and strategies Because sustainable mobility and consequently low emission vehicles (LEV) are closely related with sustainable consumption within the personal mobility this paper focuses on consumer segmentation of potential LEV buyers and their willingness to buy LEV. Results have revealed that the segment of potential alternative fuel vehicles buyers is much larger than we initially anticipated. Such vehicles are, surprisingly, also more attractive for the older population, according to our results.
\end{abstract}

Keywords: sustainable consumption, low emission vehicles, consumer segmentation, sustainable mobility

\section{INTRODUCTION}

In recent years, unsustainable consumption patterns have globally received a great attention, which was introduced via Agenda 21 and its Chapter 4. On the World Summit on Sustainable Development in 2002, where a 10-year framework programme on Sustainable Consumption and Production was confirmed, and supported by the "Marrakech Process« (Geels et al., 2015). While sustainable consumption often refers to individual and household consumption, a summary by Co- 
Chairs of the Second International Expert Meeting on the 10-Year Framework of Programmes on Sustainable Consumption and Production, held in Costa Rica 2005 identifies also "institutional consumers". Sustainable consumption was also highlighted in the Agenda 2030 and its sustainable development goals (SDGs). Especially, SDG 12 aims to ensure sustainable consumption and production (SCP) patterns and it is about promoting resource and energy efficiency, sustainable infrastructure, and providing access to basic services, green and decent jobs, and a better quality of life for all. SCP aims at "doing more and better with less", increasing net welfare gains from economic activities by reducing resource use, degradation and pollution along the whole lifecycle, while increasing quality of life by involving various stakeholders (e.g. businesses, consumers, policy makers, researchers, scientists). The challenges related to sustainable consumption are growing, and the approach to addressing them must become more intentional, comprehensive, and systematic (Prothero, 2011).

In order to foster sustainable consumption into practice (Spaargaren, 2011) is arguing that there is a necessity to find a more balanced approach, made up from bottom-up and bottom-down dynamic of change, recognizing a mutual interconnections, coshaping of human actors and objects of technological infrastructure, because sustainable consumption patterns have not yet become mainstream. (Spaargaren, 2011) also claims that sustainable consumption patterns are resulting from innovations in (chains of) practices situated within distinct consumption domains such as food, housing, mobility, leisure and clothing and personal care. Innovations in consumption practices refer to the introduction of new, more sustainable ways of 'doing', 'saying', 'knowing' and 'thinking' from the side of practitioners (Spaargaren, 2011).(Lorek and Fuchs, 2013) further distinguished between "strong" and "weak" sustainable consumption, where the "weak" approach is focusing on improving the efficiency of consumption via technological improvements, and it is limited when it comes to providing solutions to today's sustainability challenges due to its lack of attention to questions of justice, its inability to deal with the rebound effect and its neglect of overall limits. However, a "strong" sustainable consumption has to be highlighted, which is an approach focusing on the question of appropriate levels and patterns of consumption, paying attention to the social dimension of well-being, and assessing the need for changes based on a risk-averse perspective. It emphasizes social innovation as a starting point and strategically takes a technologically pessimistic position (Lorek and Fuchs, 2013).

Since potential demand, consumers' wishes, preferences and decision factors are highly important for all car brands and car dealers offering AFVs and can be related with SCP these factors have already been studied under very different conceptual frameworks and methodologies, with the main purpose of finding the right leverage to encourage demand for AFVs. However, understanding of consumer preferences is also important for policy decision-makers since they are responsible for long-term development of the transportation sector and infrastructure related to AFVs. Technological forecasts based on AFV-related research are also crucial for top managers of industry-leading car makers, who are to steer the automotive industry towards a transition to a more sustainable future (Knez et al., 2014).

Added value in sustainable consumption can be created by attracting green consumers who are willing to pay a product price premium, and by attracting green investors who are willing to pay a share price premium. Green stakeholders, such as 
green consumers and green investors, accept the price premium equivalent to the economic value of environmental impact reduction also in case of LEV. Because sustainable consumption in sector of personal mobility is related with LEV this paper focuses on consumer segmentation of potential LEV buyers and their willingness to buy LEV.

\section{METHODOLOGY}

It this study data on SCP were gathered with detailed review of published papers in scientific and professional databases. It was noted that consumer segmentation can significantly impact consumers' willingness for more sustainable transport and mobility solutions therefore consumer segmentation data were gathered. Data were gathered in a web based structured questionnaire. In this manuscript only partial data are presented. Other data were presented and published in the paper of Knez et al. (2014). Data were statistically processed and graphically presented to enable readers to visualize and understand the differences among different segments of potential LEV users and buyers.

\section{RESULTS AND DISCUSSION}

When studying sustainable consumption patterns researchers are aware that that the population in general can be divided on groups with different susceptibility on environmental issues as well as towards changing their behaviour (Anable, 2005; Carreno and Welsch, 2009). This study reveals different stakeholder groups in general Slovenian population on susceptibility of purchasing LEV in the near future. Kmeans cluster analysis was therefore undertaken to identify population segments within the Slovene driver population, resulting in three distinct segments. According to their answers on the importance of situational and environmental factors three groups were formed according to their environmental awareness and readiness to buy LEV:

- $\quad 1^{\text {st }}$ group: No-Greens (20\% of all respondents),

- $\quad 2^{\text {nd }}$ group: Go-With The Flow-Greens ( $42 \%$ of all respondents) and

- $\quad 3^{\text {rd }}$ group: Go-Greens (38\% of all respondents).

$1^{\text {st }}$ group named "No-Greens" is the group of respondents not motivated for environemental issues. The information about $\mathrm{CO}_{2}$ and other emissions is not important to them when buying a car. They are aslo not motivated to think about purchasing a LEV in the near future. "Go-With-The-Flow-Greens" have actually quite positive opinion about LEVs, however they are not planning to buy one in the near future. Only the third group named "Go-Greens" are actually very interested in buying LEV in the near future. Environmental performance of their future vehicle is very important factor for them.

Different researchers differently divide factors on consumers' willingness to buy environmentally friendly products. E.g. Laroche et al. (2001) classified them into five cathegories: demographics, knowledge, values, attitudes and behaviour. Considering some of them (e.g. gender as one of the demographic factors), Fig. 1 shows that there are only $11 \%$ of all women in the »No-green « group and the remaining $89 \%$ are a part of the other two groups meaning that women are more susceptible for LEVs. Men are on the other hand much more equally distributed through all formed segments of consumers. $29.4 \%$ of them is in $1^{\text {st }}$ group of No-Greens, $39.2 \%$ in the $2^{\text {nd }}$ group of Go-With-The-Flow-Greens and $31.3 \%$ in the $3^{\text {rd }}$ group of Go-Greens. 
Revealing that there are considerably more men than women in the "No-Green" group. That means women seems to be more ecologically conscious and interested in SCP. (Borthwick and Carreno, 2012) who made similar survey on Scotland also came to a similar conclusion.

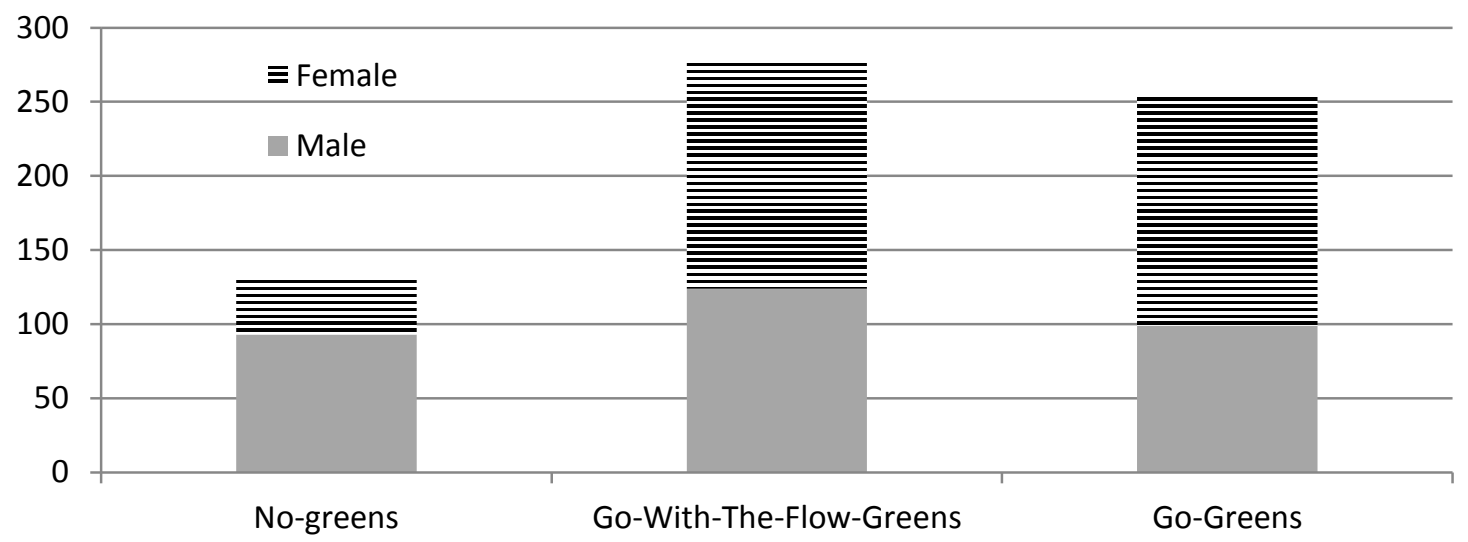

Fig. 1. Gender distribution among three segments of potential LEV consumers

Second studied factor was age distribution among three segments. Early research identified green consumer are younger than average consumers (Berkowitz and Lutterman, 1968; Anderson and Cunningham, 1972; Van Liere and Dunlap, 1981). Surprisingly, this survey show that trend has been reversed in the last decade. Several studies also identified the green consumer as being older than average (Sandahl and Robertson, 1989; Vining and Ebreo, 1990; Roberts, 1996).

This study also confirmed the above mentioned. Results are presented in Fig. 2. The majority of the No-Greens in this survey are younger than 44 years. Only $11.1 \%$ of older than 44 can be defined as No-Greens. The ratio of Go-Greens is actually increasing with age and there was not a single No-green in the group of respondents above 60 years old. One of the reasons might be that older people are more attentive about noise and health issues (related with PM emissions from traffic etc.) as well as more susceptible for sustainable purchasing instead of other marketing factors. Due to their willingness to try to make the world better for their children and grandchildren they are also more than ready to make a switch towards sustainable development.

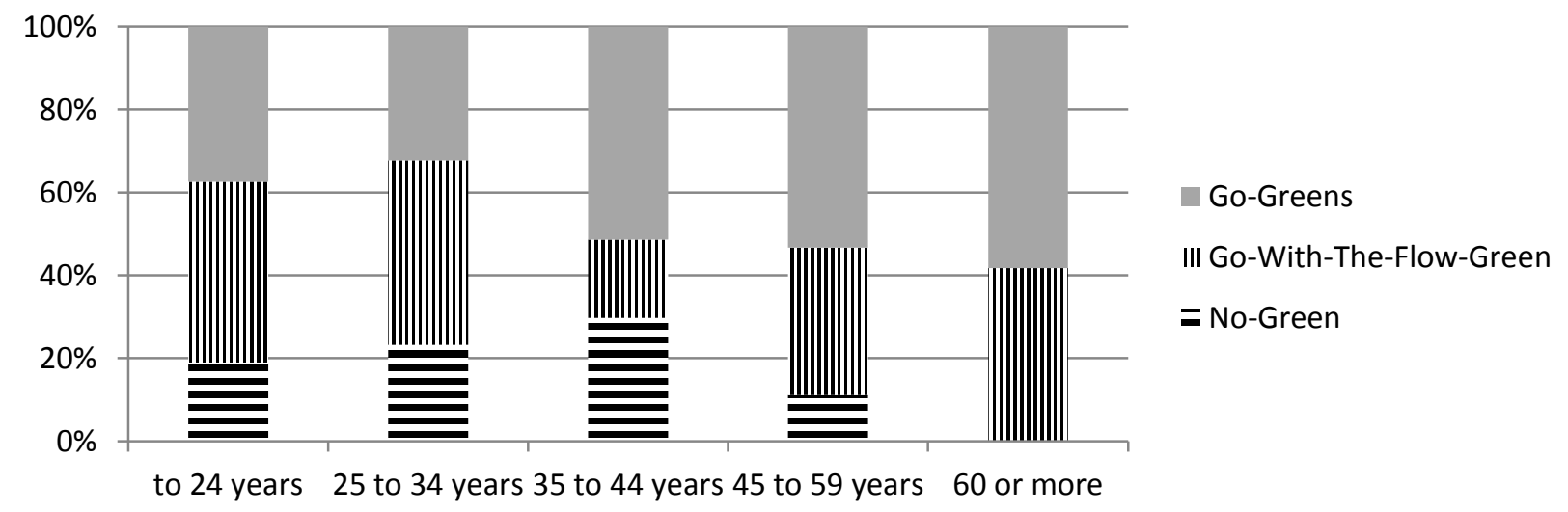

Fig. 2. Age distribution among three segments of potential LEV consumers

Even when studying LEV that can be classified as a green product that green consumers are especially interested for, additional requirements must be fulfilled to 
achieve SCP goals such as focusing on sustainable materials and technology, ecodesign, circular economy principles as well as designing environmentally sound supply chains.

\section{CONCLUSION}

SCP is actually quite new concept in sector of personal mobility and requires new knowledge to enable its fast expansion among different stakeholders. Sustainable transport and mobility is already well researched however integrating the concept of SCP with consumer segmentation was identified as a unique example of studying personal mobility. Because different stakeholders as well as different potential LEVs potential buyers and users susceptibility to buy LEV varies significantly, their segmentation is crucial to develop personalized measures for each group of consumers. Go-greens that are the most oriented towards SCP and LEV would need much smaller and less intensive incentives that for example Go-with the flow greens and No greens are probably the least interesting for policy developers dealing with LEV however they must be aware of the share of no-greens to foresee the share of possible LEV in the coming years. If e.g. the share of No-greens is $20 \%$ of total population that means that for LEV infrastructure (e.g. charging stations for electric vehicles) this part of population does not need to be taken into account because they will not have or buy LEV therefore they will not need special infrastructure related with LEV.

\section{REFERENCES}

Anable, J., 2005. Complacent Car Addicts' or 'Aspiring Environmentalists'? Identifying Travel Behaviour Segments using Attitude Theory. Transport Policy, 12 (1): 6578.

Anderson, T. Jr, Cunningham, W.H., 1972. The socially conscious consumer. Journal of Marketing, 36 (7), 23-31.

Berkowitz, L., Lutterman, K.G., 1968. The traditional socially responsible personality. Public Opinion Quarterly, 32, 169-85.

Borthwick, S., Carreno, M., 2012. Persuading Scottish drivers to buy low emission cars? The potential role of green taxation measures. Transport Research Institute, Edinburgh Napier University. Paper presented at 8th Annual Scottish Transport Applications \& Research Conference, Glasgow.

Carreno, M., Welsch, J., 2009. MaxSem: Max Self Regulation Model: Applying theory to the design and evaluation of Mobility Management projects. Available from: http://www.epomm.eu/docs/mmtools/case_studies_TA/MaxSem_applying_theory _to_MM_projects.doc (Accessed 1 September 2013)

Geels FW., McMeekin A, Mylan J, Southerton D. (2015). A crticial appraisal of Sustainable Consumption and Production research: The reformist, revolutionary and reconfiguration positions. Global Environmental Change, 34, 1-12.

Knez, M., Jereb, B., Obrecht, M., 2014. Factors influencing the purchasing decisions of low emission cars: A study of Slovenia. Transportation Research Part D, 30: 53-61.

Laroche, M., Bergeron, J., Barbaro-Forleo, G., 2001. Targeting consumers who are willing to pay more for environmentally friendly products. Journal of Consumer Marketing, 18 (6), 503-520. 
Lorek, S., Fuchs, D., 2013. Strong sustainable consumption governance e prediction for a degrowth path? J. Clean. Prod. 38, 36-43, http://dx.doi.org/10.1016/ j.jclepro.2011.08.008

Prothero, A., Dobscha, S., Freund, J., Kilbourne WE., Luchs, MG., Ozanne, LK., Thøgersen J., 2011. Sustainable consumption: Opportunities for consumer research and public policy. Journal of Public Policy and Marketing, 30(1), 31-38.

Roberts, J.A., 1996. Green consumers in the 1990s: profile and implications for advertising. Journal of Business Research, 36 (3), 217-32.

Sandahl, D.M., Robertson, R., 1989. Social determinants of environmental concern: specification and test of the model. Environment and Behavior, 21(1), 57-81.

Spaargaren, G., 2011. Theories of practices: Agency, technology, and culture. Exploring the relevance of practice theories for the governance of sustainable consumption practices in the new world-order. Global Environmental Change, 21, 813-822.

Van Liere, K.D., Dunlap, R.E., 1981. The social bases of environmental concern: a review of hypotheses, explanations and empirical evidence. Public Opinion Quartely, 44, 181-97.

Vining, J., Ebreo, A., 1990. What makes a recycler? A comparison of recyclers and nonrecyclers'. Environment and Behavior, 22, 55-73. 